\title{
The uneven spread of global science: patterns of international collaboration in global environmental change research
}

\author{
Anita Engels and Tina Ruschenburg
}

\begin{abstract}
This paper presents data on publication and collaboration patterns of USA and German research institutions in the field of global environmental change research. A dataset derived from the Web of Science showed that a marked rise in international co-authorship occured in the period 1993-2002. However, this increase covered different world regions unevenly. Building on interview data, four factors driving international collaboration in this particular research area are identified which help to explain this specific trend.
\end{abstract}

$\mathrm{I}$ deally, global environmental change research requires the free circulation of scientists, knowledge, data, and materials to be analyzed. In this field, both scientific and political reasons provide a rationale for worldwide collaborations. If the scientific goal is to provide global assessments of environmental changes it seems natural to draw on a most inclusive basis of knowledge, data and expertise. Moreover, if these global assessments are used in international diplomacy to negotiate the allocation of rights (of compensation) and duties (of regulation) with regards to environmental damage, worldwide participation in the production of this expertise becomes an issue of the credibility of the authors and the legitimacy of the assessment.

However, as every researcher in the field knows, the reality of cross-border flows of ideas, personnel and technologies is often far from smooth and obvious. This is especially true for collaborations between scientists from the Organization for

Anita Engels is at the Center for Globalisation and Governance, Faculty of Economics and Social Sciences, University of Hamburg, Allende-Platz 1, D-20146 Hamburg, Germany; Tel: ++49-(0)40-42838-3832; Email: anita.engels@unihamburg.de.

Tina Ruschenburg is at the Institute for Science and Technology Studies, University of Bielefeld, P.O. Box 100131, D33501 Bielefeld, Germany.
Economic Co-operation and Development (OECD) countries and from developing countries. While scientific infrastructures, in the widest sense, can now be found in even the remotest corners of the world (Drori et al., 2003), there are extreme (and still growing) inequalities between countries or world regions with regard to the level of research expenditures, to the existence and quality of equipment and instrumentation, technological standards etc. (Gaillard et al., 1997; Adger et al., 2005).

Katz and Martin (1997) discuss in length that scientific collaboration often entails costs, i.e. the time and resources that are needed as investments into successful research collaborations. At the same time, it is unclear to what extent additional collaborative activities pay off in the academic reward system. The ways in which a scientific reputation can be built up, or in which scarce resources are allocated over competing research proposals, influence the likeliness of international collaboration considerably. In addition to barriers within the scientific system itself, there are hurdles in its political and administrative environment in the widest sense, especially when field research is carried out abroad.

These general barriers can become even more troublesome in the wake of specific historic events. One of the most drastic events that influenced the role of geo-political borders for scientific collaboration and exchange was the terrorist attacks against the World Trade Center in September 2001. They 


\begin{abstract}
Anita Engels is professor of sociology at the Center for Globalisation and Governance at the University of Hamburg, Germany. Her research covers several societal fields in which processes of globalization occur, e.g. science and academia, environmental policies, carbon markets. She is currently working on the implications of gender in top-level research. Another research interest of hers is in the social constitution of markets. Before coming to Hamburg, she worked at the University of Bielefeld, Germany, and Stanford University, California, USA.

Tina Ruschenburg is a doctoral student at the University of Bielefeld, Germany. Trained as sociologist she is working in the field of science studies with a special focus on international collaboration and scientometrics. Her dissertation project deals with webometrics. Its main research question is whether link analysis can make substantial contributions to studying international relations within the global scientific community.
\end{abstract}

resulted among others in visa problems for foreign students and guest researchers, extensive security procedures which complicated the transport of certain (e.g. flammable) research materials, as well as restrictions on the exchange of data and materials with researchers in embargoed countries (Kennedy, 2002; Greenberg, 2002; Brumfiel, 2004; Ricks, 2004). All of these measures had the potential to limit or discourage international collaboration in at least some scientific fields.

These few examples can only highlight a few of the many barriers that researchers might face when collaborating internationally. To realize sustainable collaborations, especially between North and South, much effort from both sides is required. Nevertheless, international collaboration has increased in many fields, as numerous scientometric studies have indicated. Two general trends are broadly discussed in the literature. First, we observed a rise in the rate of multi-author papers that started in the 19th century, albeit slowly in the beginning but at a faster pace since World War I (Beaver and Rosen, 1979). Multi-author papers are widely used as an indicator of growing collaboration in science (e.g. Beaver and Rosen, 1978; 1979; Wagner-Döbler, 2001). Second, not only collaboration in general but also collaboration across national borders rose steadily; usually measured by the rate of international coauthorship of articles (e.g. Glänzel, 2001; Wagner and Leydesdorff, 2005; Leclerc and Gagné, 1994). Worldwide, the share of publications with one institutional address sank from $60.3 \%$ in 1988 to $41.3 \%$ in 2003; whereas the share of multi-author-papers within national borders rose from $31.5 \%$ to $39.1 \%$ and the share of internationally co-authored papers from $8.2 \%$ to $19.5 \%$ within the same time frame (National Science Board (NSB), 2006: Fig. 5-39).

However, two qualifications should be kept in mind. First, these trends differ largely by discipline or research field (Frame and Carpenter, 1979; Luukkonen et al., 1992; Leclerc and Gagné, 1994; de Lange and Glänzel, 1997; European Commission (EC), 2003: Fig. 5.4.3; Glänzel and Schubert, 2005;
Wagner, 2005) or even by research activities such as basic research versus applied research (Frame and Carpenter, 1979), or experimental versus theoretical research (Beaver and Rosen, 1978; Katz and Martin, 1997; Wagner-Döbler, 2001). Field sciences in particular tend to develop elaborate patterns of international collaboration as a reaction to the need for standardized nomenclature, methodologies and basic research units. In many field sciences, international congresses and international science organizations were already developed by the end of the 19th century (Crawford et al., 1993).

The second caveat applies to differences in the share of internationally co-authored papers between countries (Frame and Carpenter, 1979; Schubert and Braun, 1990; Luukkonen et al., 1992; Leclerc and Gagné, 1994; de Lange and Glänzel, 1997; Glänzel, 2001; EC, 2003: 303f; Glänzel and Schubert, 2005). Several authors identified an inverse relationship between the size of a national scientific system (in terms of scientific publications) and the importance of international co-publications (Frame and Carpenter, 1979; Schubert and Braun, 1990; Luukkonen et al., 1992; Leclerc and Gagné, 1994; Glänzel, 2001; Glänzel and Schubert, 2005). The most frequent explanation for this observation argues that larger scientific systems have a higher degree of internal differentiation and specialisation which implies that researchers find collaborators within national boundaries more easily. In smaller scientific communities a higher need for international cost-sharing is assumed.

From this overview of research on scientific collaboration we draw the following conclusions for our own research. International scientific collaboration does not occur automatically and can be costly. As we are seeing a steady increase in collaboration it is plausible to assume that several factors internal to the scientific system foster collaboration. However, the large differences between fields lead us to the question how the field of global environmental change research relates to the overall trend. This is a non-trivial question because, first, many different

Worldwide, the share of publications with one institutional address sank from $60.3 \%$ in 1988 to $41.3 \%$ in 2003 ; whereas the share of multi-author papers within national borders rose from $31.5 \%$ to $39.1 \%$ and the share of internationally co-authored papers from $8.2 \%$ to $19.5 \%$ within the same time frame 
disciplines are involved, and, secondly, the field aims at extended collaboration with partners from developing countries: collaborations which are inherently more difficult to achieve and to maintain.

Therefore, we aim to identify the drivers for international collaboration that are most important in the field of global environmental change. We are particularly interested in examining those factors that promote worldwide collaborations. Most of the cited work on research collaboration relies exclusively on quantitative measures of co-authorship. This provides important insights but cannot represent by any means the full picture of collaboration which is: '(...) a complex and heterogeneous phenomenon which cannot be sufficiently characterised by bibliometric indicators alone. International co-authorship relations represent a large range of frameworks and motivations, extending from bilateral or even multinational programmes to cooperations between individual scientists' (Glänzel, 2001: 102). Therefore, we complement this quantitative approach by adding a second perspective that draws on qualitative analysis. This combination can provide a more encompassing and at the same time more specific picture on the conditions of the particular field we are considering.

\section{Research questions}

This article addresses the question of worldwide collaboration in global environmental change research by analysing quantitative and qualitative data on cross-border scientific collaborations in the USA and Germany. In particular, we will discuss the following questions:

- How have patterns of international collaboration in the field of global environmental change research evolved in the past years (comparing USA and German research institutions)?

- Can we speak of an expansion of international collaboration, and if so, to what extent have developing countries been included in this expansion?

- What are the mechanisms driving international collaboration in global environmental change research, and do these mechanisms foster specific patterns of collaboration?

The remainder of this article is divided into four sections. In the first we will summarize the dataset used for this article, and describe our methodology. The second and third sections contain the main analysis and focus, respectively, on the quantitative analysis of international co-authorship, and on the qualitative analysis of mechanisms that account for the specific patterns that we found in USA and German global environmental change research. The final section will discuss our findings in the context of the need for more worldwide collaboration in science.

\section{Data and methodology}

The data was collected in a research project on the globalization of science in the area of global environmental change research. From previous studies on research collaboration in developing countries we know that the scientific infrastructures and the motivation to undertake efforts in globalizing research can vary enormously between countries and world regions (Engels 2008; Weingart 2006). In this study we have focused on research institutions in Germany and the USA and their specific collaboration patterns. Both countries have large, well-equipped scientific communities which exert a considerable influence on the production of global assessments of environmental changes. The extent to which our findings can be generalized is thus restricted to scientific communities of comparable size. Unfortunately, this project has not received funding for the analysis of research collaboration in a developing country. The potential limitations of this approach will be discussed in the final section.

The main sample was created by identifying almost a hundred research institutions in the USA and Germany which were of thematic relevance. Constructing a research area for bibliometric analysis is a non-trivial exercise. Global environmental change research is a special case since it is not a coherent and narrowly defined research area within clear disciplinary boundaries (Jappe, 2007). Rather there is an extraordinary variety of institutions in the field of global environmental change research with regard to thematic orientation, organizational type and size, ranging from very small university centres to huge governmental research labs. Our goal in the sampling process was to rebuild this variety since it can be assumed that those different types of research organizations feature specific collaboration patterns and motivations for collaboration.

We started the search for such institutions by interviewing experts in the fields of biodiversity or climate change research, cross-checking the institutional affiliation of well-known authors and the list of institutions generated by the interviews. In a second step, we scrutinized each institution's homepage for thematic relevance. Here, the most important selection criterion was whether or not the research conducted in the institution addressed questions of environmental changes from a global perspective, as this would almost automatically require an international orientation.

In order to avoid a thematic or organizational bias research institutions within and outside of the university system, with different sizes in terms of staff and resources, with computer-based and fieldoriented science, experimental and theoretical foci, and with research programs dedicated to global biodiversity and to global climate change have been selected. However, in order to guarantee a minimum size many German university institutions had to be excluded from further analysis as they only had one 
or two professorial chairs. A systematic comparison of the USA and German university research institutions in this sample has been provided elsewhere (Engels, 2006).

\section{Quantitative analysis of international co-authorship}

The first part of our analysis contains the quantitative evolution of international co-authorship relations in a sample of USA and German research institutions that dedicate their efforts, in part or fully, to global environmental change research.

Counting internationally co-authored publications is used as a standard measure for the analysis of patterns of scientific collaboration (Beaver and Rosen, 1978; 1979; Schubert and Braun, 1990; Luukkonen et al., 1993; Glänzel, 2001; Glänzel and Schubert, 2005). Other measures based on citations are much more time-consuming and demand a more elaborate conception of measurement. They are only rarely developed and used (e.g. Glänzel and Schubert, 2005). Co-authorship as an indicator of collaboration has been criticized because the relationship between collaboration in various phases of the research process and co-authoring the publication of an end product are far from obvious (Katz and Martin, 1997; Bordons and Gomez, 2000; Laudel, 2002). However, as the publication of results is a central aspect of scientific work, and data on co-authorship are easily available, we still think that international co-authorship provides a useful proxy for international collaboration.

From the main sample specified above, we selected those research institutions for co-authorship analysis that were founded well before the period under scrutiny (1993-2002) and that had a publication record sufficiently documented in the Web of Science database. For the investigated decade, only 54 research institutions fulfilled these criteria: 36 in the USA and 18 in Germany (see Appendix 1 for a list of institutions).

The data were downloaded from the Web of Science which comprises the Science Citation Index (expanded version), the Social Science Citation Index and the Arts \& Humanities Citation Index. They cover the period 1993-2002 and include 37,111 papers from the USA and 10,087 papers from

\section{Co-authorship as an indicator of collaboration has been criticized because the relationship between collaboration in various phases of the research process and co-authoring the publication of an end product are far from obvious}

Germany. With reference to the authors' addresses we identified articles as co-authored internationally (later called 'international articles') that had more than one country address, regardless of how many different countries were involved. We accumulated this at the national level as the percentage of internationally co-authored papers of total number of papers to be able to compare national rates of internationalization. In a second step we looked at which countries were involved, whether they were developed or developing countries, and how they were distributed geographically across the globe.

\section{Qualitative analysis of mechanisms fostering collaboration}

In addition to the quantitative analysis we conducted more than 70 qualitative interviews in the USA and Germany (see list in Appendix 2). One group of interviews was conducted with the heads of the research institutions. In Germany we visited all the leaders of the research institutions in the main sample who were available for an interview. For pragmatic reasons it was not feasible to cover all institutions from the USA main sample as they were spread right across the country. However, we were able to include some of the smaller and newer institutions that were not part of the quantitative analysis as they did not have a sufficient number of publications over a ten-year period. The interview sample rebuilt the mixture of fields, sizes and university/non-university affiliations and covered the heterogeneity of working conditions in the field.

Even though scientific collaboration occurs in many cases at the individual level, we think that the institutional level provides important additional insights into the factors which drive collaboration. Typically, the interviewees were able to clearly differentiate between the formal and strategic institutional perspective and their individual experiences as members of a specific research team.

A second group of interviews was conducted with program officers responsible for global environmental change research at national funding agencies and national academies (see list in Appendix 3). The program level adds a relevant perspective to our research as the program officers have a broad overview of the typical problems of international collaboration in science. They are often engaged in lowering the barriers for collaboration or in promoting specific forms of collaboration. They usually know about failed attempts to create new networks etc. As they are the operative link between the funding agencies and the researchers, they should also have knowledge about the connections between funding and collaboration.

In both types of interviews we asked for perceived changes in international collaboration in global environmental change research. Interviewees were asked to identify the factors influencing cross-national collaboration that they found most relevant. Here we 
followed a broader definition of collaboration than co-authorship including joint conferences, informal discussions, capacity-building projects etc. Thus, we were also able to address the question of why some forms of collaboration result in mainstream scientific publications whereas others do not.

All interviews were fully transcribed and then coded. The coding was applied, e.g. to the geographical areas covered by collaboration, to the various forms of collaboration, to the ways in which collaborations were initiated, and by whom. The different motivations for research collaborations were coded as well as the barriers and the perceived reasons for failed attempts to collaborate.

The results we describe later in this paper are thus based on a systematic analysis of the complete interview material. For reasons of brevity we will simply provide a summary of the outcomes. However, some quotes from the interviews are given throughout the text for illustrative purposes.

\section{Quantitative growth and geographical spread of international co-authorship in global environmental change research}

The annual number of papers increased throughout the entire period in both samples, as can be seen from Table 1. At the same time, the number of papers with co-authors' addresses from more than one country rose disproportionately.

As a consequence, the share of those internationally co-authored papers increases considerably in both countries: in the USA it rose from $19.8 \%$ to $37.6 \%$, in Germany from $26.9 \%$ to $50.7 \%$ (Table 2). This can be interpreted as strong evidence for a trend towards more international collaboration. A similar trend had been found in several other research fields. However, when comparing our results to general publication data, it becomes clear that both the USA and the German sample show higher-than-average levels of international co-authorship. For the period 19951999, the Third European Report on Science and Technology Indicators showed a share of internationally co-authored papers across all disciplines of
$18.0 \%$ for the USA and of $33.7 \%$ for Germany (EC, 2003: 303). In contrast, accumulating our data for the same period results in values of $28.9 \%$ for the USA and $39.1 \%$ for the German sample. This supports the idea that global environmental change research is particularly susceptible to international collaboration.

However, there is a difference in the level of international co-authorship between the two samples. Whereas the German research institutions published more than half of their papers $(50.7 \%)$ with coauthors in other countries in 2002, in the USA sample only well above one-third (37.6\%) of the articles was co-published internationally. This difference can be explained by the country-size effect described above. Indeed, it levelled out completely when papers co-published with institutions in other EU countries were treated as domestic publications for the German sample (Engels et al., 2005).

A more detailed analysis of the co-authorship data can reveal further information about the type of collaboration which underlies the described trend towards a higher degree of international co-authorship. Is it mainly based on an expansion of copublications with authors from developing countries or countries in transition, or rather on collaborations with authors from other developed countries? We classified all countries appearing in co-authors' addresses according to the UN categories: developed countries, developing countries (including least developed countries when applicable) and countries in transition. Subsequently, we calculated the share of papers with co-authors' addresses in other developed countries (resp. in developing countries, and in countries in transition) in all internationally coauthored papers (Table 3). Papers with addresses from several country groups were assigned to each of the categories, so the values in the column add up to more than $100 \%$.

In both samples, the majority of all co-author addresses are research institutions in other developed countries. Papers co-authored with institutions in developing countries and with countries in transition play a lesser role. In the German sample, the percentages of co-authorship with developed countries, developing countries and countries in transitions

Table 1. Total number of papers in samples analyzed

\begin{tabular}{lrrrrrrrrrr}
\hline & 1993 & 1994 & 1995 & 1996 & 1997 & 1998 & 1999 & 2000 & 2001 & 2002 \\
USA & 3157 & 3407 & 3435 & 3624 & 3522 & 3829 & 3834 & 3979 & 4107 & 4217 \\
Germany & 591 & 682 & 844 & 875 & 1041 & 1113 & 1113 & 1202 & 1272 & 1354 \\
\hline
\end{tabular}

Table 2. Share of internationally co-authored papers in samples analyzed

\begin{tabular}{lcccccccccc}
\hline & 1993 & 1994 & 1995 & 1996 & 1997 & 1998 & 1999 & 2000 & 2001 & 2002 \\
USA & $19.8 \%$ & $22.2 \%$ & $23.1 \%$ & $26.2 \%$ & $28.8 \%$ & $32.4 \%$ & $33.3 \%$ & $34.3 \%$ & $36.3 \%$ & $37.6 \%$ \\
Germany & $26.9 \%$ & $31.8 \%$ & $34.2 \%$ & $34.6 \%$ & $40.4 \%$ & $40.3 \%$ & $44.0 \%$ & $49.6 \%$ & $48.7 \%$ & $50.7 \%$ \\
\hline
\end{tabular}


Table 3. Share of papers with co-authors in other developed countries, in developing countries and countries in transition in all internationally co-authored papers which were analyzed

\begin{tabular}{|c|c|c|c|c|c|c|c|c|c|c|}
\hline & 1993 & 1994 & 1995 & 1996 & 1997 & 1998 & 1999 & 2000 & 2001 & 2002 \\
\hline \multicolumn{11}{|l|}{ USA } \\
\hline Developed countries & $85.9 \%$ & $85.3 \%$ & $86.3 \%$ & $84.6 \%$ & $84.8 \%$ & $84.9 \%$ & $83.5 \%$ & $84.6 \%$ & $82.7 \%$ & $81.8 \%$ \\
\hline Developing countries & $13.7 \%$ & $16.5 \%$ & $16.0 \%$ & $18.1 \%$ & $17.4 \%$ & $18.5 \%$ & $19.5 \%$ & $19.5 \%$ & $21.5 \%$ & $22.8 \%$ \\
\hline Countries in transition & $6.4 \%$ & $5.3 \%$ & $5.2 \%$ & $5.5 \%$ & $6.5 \%$ & $6.4 \%$ & $7.1 \%$ & $7.0 \%$ & $6.9 \%$ & $6.3 \%$ \\
\hline \multicolumn{11}{|l|}{ Germany } \\
\hline Developed countries & $74.2 \%$ & $79.7 \%$ & $77.2 \%$ & $77.9 \%$ & $80.8 \%$ & $78.4 \%$ & $78.8 \%$ & $80.4 \%$ & $80.3 \%$ & $75.8 \%$ \\
\hline Developing countries & $17.0 \%$ & $17.1 \%$ & $12.8 \%$ & $14.5 \%$ & $13.8 \%$ & $18.7 \%$ & $12.7 \%$ & $15.9 \%$ & $14.5 \%$ & $17.8 \%$ \\
\hline Countries in transition & $15.7 \%$ & $13.8 \%$ & $19.0 \%$ & $19.8 \%$ & $17.6 \%$ & $17.8 \%$ & $18.2 \%$ & $16.3 \%$ & $15.3 \%$ & $18.8 \%$ \\
\hline
\end{tabular}

remained quite stable. This means that the number of co-publications with each country group increased in proportion to the rising overall number of internationally co-authored papers. In the USA sample, co-publications with countries in transition remained at a very low level throughout the decade under observation. However, the share of co-publications with other developed countries decreased slightly while the share of co-publications with developing countries rose continuously from $13.7-22.8 \%$.

Altogether, the results indicate a considerable trend towards more international co-authorship in global environmental change research in the period 19932002. Whereas this development seems to be a mere intensification of older co-authorship patterns in the German sample, in the USA sample this trend is partly based on disproportionately increasing coauthorship with developing countries. This points to a recent expansion of collaborations between North and South at least in USA global environmental change research. A finer-grained analysis, not included in the tables, shows that this expansion is mainly restricted to Central and South America as well as East Asia. Truly marginal regions, e.g. in Africa or South-East Asia, were not included in the growth trend.

This analysis of co-authorship data therefore raises further questions: Which explanations for the detected trends (increasing international coauthorship; especially with emerging countries in the USA sample) can be found? How do collaborations with partners in other developed countries differ from those with developing countries? What mechanisms are behind the selective expansion of coauthorship to developing countries, i.e. the almost complete exclusion of the truly marginal developing countries in Africa and South-East Asia?

\section{Factors influencing international collaboration in global environmental change research}

Numerous factors influencing international collaboration in science have been discussed in the literature. Most authors point to economic reasons in the broadest sense (de Lange and Glänzel, 1997): collaboration often incurs improved access to resources and equipment or, more colloquially, to " "stuff" one doesn't have' (Beaver, 2001: 373). Others mention that regional organizations provide additional funding for international collaboration within the region because this serves political objectives, e.g. with respect to improved scientific collaboration within the European Community (Luukkonen et al., 1992; 1993). Motivations for collaboration vary with the type of collaboration that is aimed at: division of labor, service collaboration, transmission of knowhow, provision of access to research equipment, trusted assessorship and mutual stimulation have been enumerated in a study by Laudel (2002). Some authors have noted that changes in the patterns of collaboration can be observed most clearly in developing countries and in economies in transition (de Lange and Glänzel, 1997). However, much of that body of work does not link the empirical analysis of collaboration patterns in selected research areas to the factors that are specifically influential in these areas. Moreover, few authors have addressed the question of how collaborations with partners in developed countries differ from those with developing countries and how this might be reflected in coauthorship data. Finally, reasons for scientific collaboration are often discussed from the perspective of individual researchers (e.g. Beaver, 2001; Laudel, 2002). We are aiming to analyze the more strategic level of research institutions and national or regional research programs in addition to the individual level of research collaboration. The following paragraphs summarize our findings from the qualitative analysis we described above.

Areas of relevance for global environmental change research are very often located in world regions which are marginal in terms of economic development, geopolitical importance, and also scientific literacy (Gaillard et al., 1997). Many areas in Africa or South-East Asia which are particularly rich in biodiversity lack an equally rich scientific infrastructure to provide a deep analysis of their changing ecosystems (Gaillard et al., 2001). In order for the capacity of global environmental change 
research to generate the full (global) picture of environmental changes, it is therefore important to either build up scientific infrastructure in these areas or secure access to these areas and rely on collaboration and exchange with local scientists. However, the motivation of research institutions to make additional efforts to build up collaborations and to secure worldwide access to data and to the field varies considerably (Dahdouh-Guebas et al., 2003). The systematic analysis of our interview data revealed a wide spectrum of strategies and motivations. At one end, universities or even governments invest in highend research collaborations with respected first-class research partners in other countries:

[Princeton and Oxford fund sort of a partnership [...], and they try to build on each other's strength. [...] And so by working together you get in fact a larger group and so the PrincetonOxford link is trying to do that... (EEB, 12 March 2003)

There are people here working within the socalled Cambridge-MIT-Initiative in which... the British Government put up a very large amount of money to encourage the University of Cambridge and England to establish partnerships with MIT people. [...] That partnership involves an agreement between the University of Cambridge and MIT at the very highest level. (PAOC, 1 April 2003)

At the other end of the spectrum, the conditions for collaboration are more based on inequality which then leads to an asymmetrical relation. The rational behind it is rarely high scientific quality but rather the moral obligation to help and to support local scientists. Thus the expected outcomes do not necessarily include improved hard data but have to do with softer indicators such as contextual knowledge.

Local scientists bring a flavour about what are the really significant cultural and economic issues as well, and so naturally we are going to co-author, and build collaborations, we are going to support the development of the infrastructure in those countries by supporting master students and $\mathrm{PhD}$ students. [...] By working with Kenyans it takes on a local flavour. (EEB, 12 March 2003)

A specific motivation for a more global pattern of research collaboration comes with the rising importance of global environmental assessments. The importance of equal geographical representation of researchers and sources of knowledge for the legitimacy of the assessments of the Intergovernmental Panel on Climate Change has been widely discussed. Obviously, this also refers to more recent programs such as the Millenium Ecosystem Assessment (MA):
The assessment process, just by its very nature and the structure it has, it fosters international science because [...] in a global biodiversity assessment [...] you got to have the best scientists distributed around the world to engage in that. It has to be the world community doing this. (MA, 16 March 2004)

This can lead to very specific problems in creating a new global knowledge basis from a heterogeneous set of sources from around the world:

You have got to have published peer-reviewed literature. We will be using a lot of traditional knowledge for example. So how do you use traditional knowledge in an assessment context? (MA, 16 March 2004)

Notwithstanding potential costs of collaboration and a huge variety of resulting problems, many researchers and research institutions deliberately try to increase the international component of their daily work. Out of the various factors influencing scientific collaboration discussed above, we identified four distinct mechanisms in our interview data that were of particular relevance for the researchers and the institutions in our sample. In the following, we summarize these mechanisms and link these findings to the results of the quantitative analysis.

\section{Scientific competition and strategic collaboration among equals}

Even though many research collaborations emerge spontaneously, a heightened sense of competition for scarce resources drives some research institutions to search strategically for strong partners for collaboration. In this search, they increasingly look for international collaboration. They target institutions that are comparable in strength, resources and reputation, in order to mutually enhance the chances for obtaining more funds in the future. For top-end German research institutions, typically UK or USA research institutions are the most attractive ones. Both partners bring in substantial resources at a sophisticated level of technology or methodology:

Currently we are preparing a project together with NCAR on Mexico City, to which we will contribute with models and with airborne measurements. We converted a microlight into a flying laboratory, and this can contribute to the project. (IFU, 10 May 2004)

By creating synergies and combining complementary profiles, a higher level of excellence can be reached for both partners. In practical terms, joining scarce resources allows for larger and better projects. This is not a new phenomenon as such (Beaver and Rosen, 1978). However, we found that even USA institutions in the field of global environmental 
change increasingly look abroad to find this type of partnership among equals.

Economics has fuelled some of these collaborations to some extent and in particular in expensive programs, there are limits to how much money we can get out of any single government to do a project. If we can collaborate with someone in Europe who has a different source of money that we can use as leverage to say 'look, they are putting in money, it won't cost you much if you give us and you get a bigger project'. And everybody wins when we do that. (COAS, 3 April 2003)

For these partnerships to be realized it is important that research institutions feel on an equal footing with each other:

These institutions are very similar to us, so obviously we do some of the things together. (MPI, 28 June 2004)

Of course these are natural collaborations. (COAS, 3 April 2003)

All the main players in weather and climate I would say we have relationships with. (NCAR, 14 April 2003)

A growing need for this kind of partnership is readily acknowledged at the program level, even though this acceptance rarely leads to genuinely shared programs but rather to the combination of resources by different national funding agencies.

If we do it right, we can leverage each others investments. (NASA, 23 February 2004)

Collaborations between equal partners very often lead to long-term exchange relations: the frequency of the research contacts creates a level of trust and mutual understanding that easily leads to joint publications in peer-reviewed journals.

\section{Growing network density in politically meaningful regions}

A second mechanism can be best described as a politically motivated incentive structure to support a growing density of scientific exchanges in politically meaningful regions. Obviously when states are directly involved with funding and defining research programs, political goals can become part of a hidden agenda. This has been a longstanding tradition in the field of scientific collaboration with the former Soviet Union. As a more recent example, many interviewees in both the USA and Germany mentioned some degree of political pressure to initiate research collaborations with China. However, in addition to these bilateral incentives, there are

\section{Many interviewees in both the USA and Germany mentioned some degree of political pressure to initiate research collaborations with China}

regional programs that have become important in the field of global environmental change research. For the German research institutions, EU research funding is a strong driver to build up networks with more and more European partner institutions. Many of the German interviewees mentioned that these programs are of growing importance for the overall budgets of their research institutions, and that the European research landscape has changed dramatically as a result of the programs.

The structure of the EU research programs creates very strong incentives. In general one can only receive funding by the Commission through the framework programs if one has several European partner institutions directly involved. Research in the whole of Europe has been set in motion. Now everyone collaborates with anyone else. (WI, 22 July 2003)

I left Germany in 1990, and when I came back to Europe in 1999, I could not believe how international the EU had become. So many people worked in other countries, so many Germans in Scandinavia, so many Dutch in Germany, Germans in the Netherlands, in a way that had been unimaginable only 15 years ago - as a matter of course. (MPI, 28 June 2004)

However, the USA interviewees also mentioned several examples where the USA government or private foundations funded programs to promote scientific collaboration with Central and South America as well as with the Pacific Rim states. The rationale for such programs can be to strengthen scientific ties as a basis for innovative capacities and economic growth, or to promote ties within a region of specific geo-political importance.

So now there is this Pacific Rim group meeting at the same time, and the purpose of that is in a way capacity building. How do we engage this community, let them have their own planning, let them speak their minds. (NAS, 24 February 2004)

To date we contributed just over 20 million dollars to the organisation [the Inter-American 
Institute for Global Change Research, IAI]. The larger part of that has gone into actual collaborative research networks that have been formed. (NSF, 25 February 2004)

There are requirements for anybody who is funded [by the IAI] to be explicitly international. So you know you have to have an investigator from Mexico and Chile and Ecuador working together. (NAS, 18 March 2004)

As individual researchers, many interviewees expressed scepticism about this type of enforced network strategy. Regional programs typically incur a considerable degree of artificial networks that rarely result in a coherent research approach. Instead of synergies, many researchers fear a loss of quality as a result of the politically motivated programs of regional scientific integration (Pereira, 2002; Okubo and Zitt, 2004). However, the data on co-authorship seems to indicate that it has a least some effect in terms of international publications.

\section{Capacity building for marginal scientific communities}

A third mechanism has become important in the context of international conventions and global environmental diplomacy. It specifically aims at expanding international collaboration to marginal world regions, i.e. to developing countries that have so far lacked the required infrastructure and know-how to participate in the mainstream production of scientific knowledge.

We are also working with the drought monitoring centres in Nairobi and in Harare to try to bring up their capacity to undertake research and understanding the regional elements of the climate as opposed to the global scale. (IRI, 10 March 2003)

So that we are strengthening institutional capacities in the country we are working in so that they can then take a much greater role in doing these projects. (CBC, 11 March 2003)

Every single meeting I go, virtually every single meeting I go to, capacity building is an issue. (MA, 16 March 2004)

The nexus to the international conventions is obvious: global assessments play an important role as input to the negotiations and for the exact wording of the conventions. Moreover, most conventions call for a permanent global monitoring of those processes and systems covered by the conventions. Since the early 1990s it has become conventional wisdom that equal geographical representation of scientists is of crucial importance for the acceptance and legitimacy of global assessments and global monitoring procedures. For instance, all parties to the Convention on Climate Change are obliged to produce scientific documents on the domestic relevance of global climate change, and bilateral and international programs for capacity building have been founded to enable individual countries to prepare their documents. The global diffusion of research activities can be found in the context of virtually all international conventions on global environmental change.

There is little local capacity or regional capacity in huge regions to address major environmental problems of water pollution, climate change, whatever else. So we all invest a big effort in trying to build that capacity and the Millennium Assessment is one major way in which that's happening. (CCB, 9 April 2003)

Scientific training and the use of standardized procedures are both means of bridging the enormous gap between the scientific standards of these international negotiations and the existing scientific capacities in marginal developing countries. However, the relationship remains asymmetrical.

If you have 8 to 10 centres around the world that means that most countries actually can't play. So for much of the developing world part of the challenge is how do you engage them, how do you make the data sets available, how do you train them to use these things. They are not going to build their own models, it's too complicated. (GFDL, 12 March 2003)

In many areas we are not dealing with high tech but we are rather engaged, so to speak, in development aid. (FAL, 14 June 2004)

This raises the question to what extent asymmetrical research collaborations can result in co-authored journal articles. Most interviewees acknowledged a kind of moral obligation to try to co-author papers with colleagues from developing countries. However, this seems to require an extra effort and is often perceived as a matter of goodwill rather than a fair arrangement reflecting the real intellectual input. And many times practical problems occur, in particular when the partners in developed countries 'need' the publication for their own career advancement.

Well, the idea was to set up partner teams with one German and one Guatemalan Ph.D. student, in the same way we always do it in Indonesia. However, there is no Ph.D. program in Guatemala, the students cannot get their Ph.D. in their country, so this was not possible. Rather on the contrary, even our master students, they sometimes wrote small articles, and they did that on their own. (IZNE, 18 May 2004) 
Capacity-building activities are found at both the program level and at the individual level. In addition to the START program which is specifically dedicated to capacity building in global environmental change research, there are many more general programs, e.g. those funded by UN organizations or by private foundations.

The Academy is well on the way of getting money from the Gates Foundation to do a capacity building program with academies of sciences in Africa, with the expressed purpose of building up the scientific capacity through academies of sciences. (NAS, 24 February 2004)

Many interviewees, both at the institutional level and as individual researchers, expressed their conviction that capacity building is and should be part of their standard research practice. However, this asymmetrical form of collaboration does not automatically lead to co-authored research articles. This is a possible explanation why the often huge investments in capacity building are not reflected in the data on co-authorship patterns where scientific communities in marginal developing countries remain virtually excluded.

\section{Collaboration fostered by control over field access}

A fourth mechanism has also emerged in the context of international conventions on global environmental change. It is grounded in the specificity of field sciences:

We have to work in other people's countries, we have to work in other people's territories or waters. So you naturally have to involve scientists from other nations, so there is naturally an international aspect to it. (LDEO, 10 March 2003)

There really are some hotspots of global change. They are occurring in the developing world. You know the Brazil rainforest and Africa, you know these are the sights. (NAS, 24 February 2004)

It is well known that in field sciences the need to be 'on site' often triggers scientific collaboration, above all if the scientific infrastructure is well developed in the country of interest (Thorsteinsdóttir, 2000). However, this was rarely the case in developing countries. Only in recent decades have the conditions for collaboration between 'northern' scientists and their 'southern' counterparts changed substantially. It used to be common practice for scientists from Europe or North America to do field research or to take out samples from other countries without officially notifying the country concerned. It was possible to completely ignore local scientists or research institutions. Now, international conventions and national legislations regulate the possibilities of access to national territories by foreign researchers. The Biodiversity Convention, effective since 1993, clearly states that decisions about how to protect and how to make use of biological resources and biological diversity are under the responsibility of the nation-state to whom the respective territory belongs. It enables governments to regulate access to and exploitation of their natural resources. To the extent that researchers need access to the regions where a particular species or ecosystem occurs, their authorization can be made dependent on a formal collaboration with local counterparts, on joint publications, the transfer of research money etc.

The data problem has become more difficult. Satellite data are not always sufficient. However, after the decolonization process it has become more difficult to get in-situ data. (MIUB, 28 April 2004)

The actual capacity of developing countries to control access to their territories and the species therein, however, varies considerably. Countries with socalled hot spots of interest for 'northern' researchers include: Brazil, Mexico, Indonesia, India etc. These countries have highly developed administrative infrastructures and often have enough institutional clout to control or oversee research activities in their territories. Thus, some governments of countries that are rich in biodiversity can almost 'enforce' scientific collaboration between incoming researchers and local institutions.

That's the only way we can get access to work e.g. in Indonesia is to have a collaboration with an Indonesian scientist. (WHOI, 4 March 2003)

So Brazil when I worked there and even now has been very, very rigorous about what you can walk away with. In some ways enforced the idea of collaboration and control. (NAS, 18 March 2004)

Co-authored publications are sometimes seen as 'tickets' to field access (FIS, 25 May 2004). Funding agencies increasingly realize that these conditions call for changes at the program level.

So if a professor in some university in another country says, will you fund my graduate students, the answer is almost certainly no. [...] There are certain exceptions like when we do field work in Brazil for the large scale biosphere Amazon. [...] I think anyone even the U.S. who goes down there is expected to bring in Brazilian collaborators whether it's students or working with faculty there. And the idea was that for the privilege of coming into their 
country and working, we are expected to leave something behind and not just take our science and run. (NASA, 23 February 2004)

It's almost impossible, in Mexico for example where I worked at for years, we wouldn't think of working in Mexico anymore without really having the centre of gravity for the project to be Mexican scientists and Mexican students. (NSF, 23 February 2004)

We have a memorandum of understanding, they come on board, in any case they get the data, as it is data on their national coastline. Still we have problems, as the Brazilians want real development programs or real collaboration. (DFG, 5 July 2004)

At the program level, this often creates new challenges because research funding is still predominantly organized within national boundaries. However, this mechanism for collaboration may help to understand the disproportionate expansion of co-authorship relations with some countries in Central and South America and in East Asia.

To summarize, these four mechanisms all influence international scientific collaborations of the research institutions we analyzed, yet in very different ways. The first, 'strategic search for equal partners' clearly concerns collaborations with partners in other OECD countries. The second, however, has different implications for the USA and Germany. Whereas the 'political promotion of regional networks' in Germany mainly refers to the EU, the same mechanism leads to increased collaborations between developing countries and the USA (namely Central and South America, Pacific Rim region). The identified mechanisms therefore correspond with the observed trends in the quantitative analysis on co-authorship which shows an intensification of international collaborations within established partnerships in both countries plus a disproportionate growth of collaborations between USA researchers and (some) developing countries. The first two mechanisms, therefore, can lend plausibility to the quantitative findings presented earlier.

The last two mechanisms, 'capacity building' and 'control over field access', mainly refer to collaborations with developing countries. The former particularly targets marginal world regions with low scientific capacities; the latter varies more strongly and is more important in countries that already have more elaborate elements of scientific (and administrative) infrastructures. Even though 'capacity building' is a way of including scientists in a worldwide process without regional limitations, this mechanism does not necessarily lead to formal co-authorships for articles that would appear in mainstream journals and would thus be counted in our database. By using 'control over field access', however, local research institutions are in a better position to demand formalized collaborations or even co-authorship, and countries in which this occurs produce more input into the mainstream production of scientific literature. In this sense, also the last two mechanisms support our quantitative findings, as only the more powerful developing countries have the potential to effectively promote co-author relationships.

\section{Conclusions}

We have analysed data to answer several questions which are summarized below. Measured by international co-author relations, international collaboration in the field of global environmental change research has gone through a distinct and continuous rise. The percentage of internationally co-authored papers of all papers has almost doubled in only a decade. This trend reflects the general tendency towards more international collaboration in scientific literature, but the level is much higher in global environmental change research than the average across all fields.

Further analysis demonstrates an expansion of international collaboration that covers different world regions unevenly. Even though there is a disproportionately high rise in international co-authorship with authors from developing countries in the USA papers, this reflects only a small selection of developing countries and leaves out most of the truly marginal scientific communities in Africa and South-East Asia.

The mechanisms influencing international collaboration in our sample of research institutions lend plausibility to this finding: the rise of co-authorships with some developing countries mostly includes countries that already have a well-developed scientific and administrative infrastructure. These countries can effectively control access to sites of interest for global environmental change research and can link access to the field more systematically to scientific collaboration that leads to mainstream science co-authored publications. In addition, some of these countries can be found in geographical regions that are politically meaningful to the USA so that extra funding for collaboration and networking activities can be channelled into these regions. Less developed countries outside of these regions often receive funding for capacity-building programs. This type of capacity building, however, is characterized by asymmetrical scientific exchanges and rarely includes joint publications in high-end scientific journals.

This research project has focused on motivations for and barriers to international research collaborations as seen and experienced by researchers in the USA and Germany. We have not been able to provide the complementary perspective of collaboration as seen and experienced by researchers from developing countries. Drawing on earlier research on the adoption of global climate change policies and programmes in Senegal, we assume that the conditions 
for international collaboration vary significantly in smaller and more marginal scientific communities. At the individual level, many researchers feel strongly attracted by USA or European science centres. Access to high-tech research methods and equipment, invitations to international conferences, and publications in prestigious journals all serve personal career advancement. At the institutional level, other motivations to engage in collaborations with researchers and research programs from developed countries become important. For instance, a meaningful inclusion in the production of global environmental assessments requires advanced know-how and theoretical understanding that is usually not provided by standard methodology trainings. Moreover, external funding often depends on the formal independence of the research institution from the control and supervision of state authorities. More autonomy for research institutions might therefore be a side-effect of collaborations with 'northern' partners. However, in most cases collaboration occurs under conditions of inequality, and the outcome is often a bundle of discontinuous research activities in which the agenda is set according to external criteria, and the control over financial resources and technological equipments remains firmly in the hands of the 'northern' partners (Engels 2003; 2008). Clearly a more systematic complementary research perspective would be desirable to understand the various factors driving worldwide patterns of scientific collaboration in both developed and developing countries.

To summarize our results, some of the mechanisms occurring in developed countries explicitly foster scientific collaboration with developing countries. However, given the growing degree of inequality between countries these mechanisms are simply not strong enough to produce a more egalitarian participation in the mainstream production of scientific knowledge. A truly global spread of scientific participation might become more important in the future of global environmental change research (and related policy programs), but will still be very difficult to achieve.

Global environmental change research requires the production of global knowledge. A more equal representation of world regions in the process of knowledge production can bring important quality improvements to global assessments. A broader inclusion of developing countries into this process also increases the legitimacy and credibility of global assessments as a support for international environmental diplomacy. International research programs should therefore become more aware of the selectivity of the collaborations they promote. Programs for capacity building in developing countries should not limit themselves to providing basic training and equipment but should seek to link these measures more systematically to the scientific mainstream.

\section{Appendix 1. Sample of research institutions covered in the bibliometric analysis}

\section{In Germany:}

Alfred-Wegener-Institut für Polar- und Meeresforschung, Bremerhaven

Biologische Bundesanstalt für Land- und Forstwirtschaft, Braunschweig

Botanisches Institut und Botanischer Garten, Rheinische Friedrich-Wilhelms-Universität, Bonn

Bundesforschungsanstalt für Landwirtschaft, Braunschweig

Deutsche Sammlung von Mikroorganismen und Zellkulturen,

Braunschweig

Deutsches Klimarechenzentrum, Hamburg

Deutsches Primatenzentrum, Göttingen

Forschungsinstitut Senckenberg, Frankfurt a.M.

Fraunhofer-Institut für Atmosphärische Umweltforschung,

Garmisch-Partenkirchen

Institut für Allgemeine Botanik und Botanischer Garten, Universität Hamburg

Institut für Küstenforschung, GKSS, Geesthacht

Institut für Ökologie, Friedrich-Schiller-Universität, Jena

Institut für Pflanzengenetik und Kulturpflanzenforschung,

Gatersleben

Institut für Zoo- und Wildtierforschung, Berlin

Max-Planck-Institut für Meteorologie, Hamburg

Meteorologisches Institut, Rheinische Friedrich-Wilhelms-

Universität, Bonn

Potsdam Institut für Klimafolgenforschung, Potsdam

Zoologisches Forschungsinstitut und Museum Alexander König, Bonn
In the USA:

Atlantic Oceanographic and Meteorological Laboratory, Miami, FL Atmospheric Sciences Competency, NASA Langley Research Center, Hampton, VA

Center for Conservation Biology, Department of Biological Sciences, Stanford University, Stanford, CA

College of Forest Resources, University of Washington, Seattle, WA

College of Oceanic Atmospheric Sciences, Oregan State University, Corvallis, OR

Department of Ecology and Evolutionary Biology, Princeton University, Princeton, NJ

Department of Natural Resources, Cornell University, Ithaca, NY

Department of Oceanography, Texas A\&M University, College Station, TX

Earth Sciences Division, Oak Ridge National Lab, Oak Ridge, TN

Energy and Resources Group, University of California, Berkeley, CA

Environmental Studies Department, University of California, Santa Cruz, CA

Geophysical Fluid Dynamics Laboratory, NOAA, Princeton, NJ Global Environmental Change Program, Department of Environmental Sciences, University of Virginia, Charlottesville, VA Goddard Institute for Space Studies, Columbia University, NY

Goddard Space Flight Center, NASA, Greenbelt, MD

Institute of Global Environment and Society, Calverton, MD

Lamont-Doherty Earth Observatory, Columbia University, Palisades, NY

Lubchenco/Menge Lab, Department of Zoology, Oregon State University, Corvallis, OR 
Appendix 1. (continued)

In the USA:

Missouri Botanical Garden, St. Louis, MO

National Center for Atmospheric Research, Boulder, CO

National Geophysical Data Center, Boulder, CO

Natural Resource Ecology Laboratory, Colorado State University

Fort Collins, $\mathrm{CO}$

Naval Postgraduate School, Monterey, CA

Pacific Marine Environmental Laboratory, Seattle, WA

Program for Climate Model Diagnosis and Intercomparison,

Lawrence Livermore National Laboratory, Livermore, CA

Program in Atmospheric and Oceanic Sciences, University of Colorado, Boulder, CO

Rosenstiel School of Marine and Atmospheric Science, University of Miami, FL
School of Natural Resources and the Environment, University of Michigan, Ann Arbor, MI

School of Ocean and Earth Science and Technology, University of Hawaii, $\mathrm{HI}$

Scripps Institution of Oceanography, University of California, San Diego, CA

Smithsonian Environmental Research Center, Edgewater, MD

Wisconsin State Herbarium, Department of Botany, University of Wisconsin, Madison, WI

Woods Hole Oceanographic Institution, Woods Hole, MA

Woods Hole Research Center, Woods Hole, MA

World Resources Institute, Washington, DC

\section{Appendix 2. List of research institutions at which interviews were conducted}

In Germany:

Albrecht-von-Haller-Institut für Pflanzenwissenschaften der Georg-August-Universität, Göttingen

Alfred-Wegener-Institut für Polar- und Meeresforschung, Bremerhaven

Botanisches Institut und Botanischer Garten, Rheinische Friedrich-Wilhelms-Universität, Bonn

Bundesforschungsanstalt für Landwirtschaft (FAL), Braunschweig

Deutsche Sammlung von Mikroorganismen und Zellkulturen, Braunschweig

Deutsches Klimarechenzentrum, Hamburg

Deutsches Primatenzentrum, Göttingen

Forschungsinstitut Senckenberg (FIS), Frankfurt a.M.

Fraunhofer-Institut für Atmosphärische Umweltforschung (IFU), Garmisch-Partenkirchen

Göttinger Zentrum für Biodiversitätsforschung und Ökologie, Georg-August-Universität, Göttingen

Institut für Evolution und Ökologie der Tiere, Westfälische Wilhelms-Universität, Münster

Institut für Evolutionsbiologie und Ökologie, Rheinische Friedrich-Wilhelms-Universität, Bonn

Institut für Allgemeine Botanik und Botanischer Garten, Universität Hamburg

Institut für Küstenforschung, GKSS, Geesthacht

Institut für Pflanzengenetik und Kulturpflanzenforschung, Gatersleben

Institut für Zoo- und Wildtierforschung, Berlin

Interdisziplinäres Zentrum für Nachhaltige Entwicklung (IZNE), Georg-August-Universität, Göttingen

Max-Planck-Institut für Meteorologie (MPI), Hamburg

Meteorologisches Institut (MIUB), Rheinische Friedrich-WilhelmsUniversität, Bonn

Potsdam Institut für Klimafolgenforschung, Potsdam

Wissenschaftliches Zentrum für Umweltsystemforschung, Universität Gesamthochschule Kassel, Kassel

Wuppertal Institut für Klima, Umwelt, Energie GmbH (WI), Wuppertal

Zentralstelle für Agrardokumentation und -information am BMVEL, Bonn

Zoologisches Forschungsinstitut und Museum Alexander König, Bonn

\section{In the USA:}

Atmospheric Sciences Competency, NASA Langley Research Center, Hampton, VA

Center for Biodiversity and Conservation (CBC), American Museum of Natural History, New York, NY

Center for Conservation Biology (CCB), Department of Biological Sciences, Stanford University, Stanford, CA

Center for Environmental Science and Policy, Institute for International Studies Stanford University, CA

Center for Global Change Studies, MIT, Cambridge, MA

Climate Diagnostics Center, NOAA-CIRES, University of Colorado, Boulder, CO

Climate Monitoring and Diagnostics Laboratory, NOAA, Boulder, $\mathrm{CO}$

College of Forest Resources, University of Washington, Seattle, WA

College of Oceanic Atmospheric Sciences (COAS), Oregan State University, Corvallis, OR

Department of Ecology and Evolutionary Biology (EEB), Princeton University, Princeton, NJ

Earth System Science Interdisciplinary Center, University of Maryland, College Park, MD

Fort Collins Science Center, Fort Collins, $\mathrm{CO}$

Geophysical Fluid Dynamics Laboratory (GFDL), NOAA, Princeton, NJ

Goddard Institute for Space Studies, Columbia University, NY

Goddard Space Flight Center, NASA, Greenbelt, MD

International Research Institute for Climate Prediction (IRI),

Lamont-Doherty Earth Observatory/Columbia University, Palisades, NY

Lamont-Doherty Earth Observatory (LDEO), Columbia University, Palisades, NY

Lubchenco/Menge Lab, Department of Zoology, Oregon State University, Corvallis, OR

National Center for Atmospheric Research (NCAR), Boulder, CO

National Geophysical Data Center, Boulder, CO

National Institute for Global Environmental Change, Davis, CA

Natural Resource Ecology Laboratory, Colorado State University, Fort Collins, $\mathrm{CO}$

Naval Postgraduate School, Monterey, CA

Pacific Marine Environmental Laboratory, Seattle, WA

Program for Climate Model Diagnosis and Intercomparison, Lawrence Livermore National Laboratory, Livermore, CA

Program in Atmospheric and Oceanic Sciences, University of Colorado, Boulder, CO

Program in Atmospheres, Oceans, and Climates (POAC), MIT, Cambridge, MA

Smithsonian Environmental Research Center, Edgewater, MD

Sustainable Ecosystem Institute, Portland, OR

Woods Hole Oceanographic Institution (WHOI), Woods Hole, MA

Woods Hole Research Center, Woods Hole, MA 


\section{Appendix 3. Programs/funding agencies at which we interviewed program officers}

\section{In Germany:}

Ministry of Education and Research (BMBF), Bonn

- Global Change Program

German Research Council (DFG), Bonn

- Division of Environmental Science

- Division of Botany

- Division of Oceanography

German Aerospace Center, Project Management Agency (PT-DLR), Bonn

- Division of Climate Research Programs

- Division of Biodiversity Programs

German Advisory Council on Global Change (WBGU), Berlin

\section{In the USA:}

National Academy of Science (NAS), Washington, DC

- Board on International Scientific Organizations

- Committee on the Human Dimensions of Global Change

- Coordinating Committee on Global Change

- Polar Research Board/Board on Atmospheric Sciences and Climate

National Atmospheric and Space Administration (NASA),

Washington, DC

- Office of Earth Science

National Oceanic and Atmospheric Administration (NOAA), Silver Spring, MD

- Office of Oceanic and Atmospheric Research

National Science Foundation (NSF), Arlington, VA

- Biodiversity Surveys and Inventories

- Directorate for Geosciences

Millenium Ecosystem Assessment (MA), Board Member, Stanford

University

\section{References}

Adger, Neil W, Katrina Brown, Mike Hulme 2005. Editorial. Redefining global environmental change. Global Environmental Change, 15, 1-4.

Beaver, Donald DeB 2001. Reflections on scientific collaboration (and its study): past, present, and future. Scientometrics, 52(3), 365-377.

Beaver, Donald DeB, Richard Rosen 1978. Studies in scientific collaboration. Part I. Professional origins of scientific coauthorship. Scientometrics, 1(1), 65-84.

Beaver, Donald DeB, Richard Rosen 1979. Studies in scientific collaboration. Part III. Professionalization and the natural-history of modern scientific co-authorship, Scientometrics, 1(3), 231-245.

Bordons, María, Isabel Gómez 2000. Collaboration networks in science. In The Web of Knowledge: a Festschrift in Honour of Eugene Garfield, Blaise Cronin and Helen Barsky Atkins eds., pp. 197-213. Medford, New Jersey: Information Today.

Brumfiel, Geoff 2004. As one door closes... Nature, 427, 15 January 2004, 190-195.

Crawford, Elisabeth, Terry Shinn, Sverker Sörlin eds. 1993. Denationalizing Science. The Contexts of International Scientific Practice. Dordrecht, The Netherlands: Kluwer.

Dahdouh-Guebas, Farid, J Ahimbisibwe, Rita van Moll, Nico Koedam 2003. Neo-colonical science by the most industrialised upon the least developed countries in peer-reviewed publishing. Scientometrics, 56, 329-343.

De Lange, C, Wolfgang Glänzel 1997. Modelling and measuring multi-lateral co-authorship in international scientific collaboration. Part 1. Development of a new model using a series expansion approach. Scientometrics, 49(3): 593-604.

Drori, Gili, John W. Meyer, Francisco O. Ramirez, Evan Schofer 2003. Science in the Modern World Polity. Stanford, Florida: Stanford University Press.

Engels, Anita 2003. Die geteilte Umwelt. Ungleichheit, Konflikt und ökologische Selbstgefährdung in der Weltgesellschaft. Weilerswist, Germany: Velbrück Wissenschaft.

Engels, Anita 2006. Globalisierung der universitären Forschung. Beispiele aus Deutschland und USA. Die Hochschule, 15(1), 115-133.

Engels, Anita 2008. Local environmental crises and global sealevel rise - the case of coastal zones in Senegal. In Culture and the changing environment, eds. Michael Casimir and Ute Stahl eds., pp. 175-195. Oxford and New York: Berghahn.

Engels, Anita, Tina Ruschenburg, Peter Weingart 2005. Recent internationalization in global environmental change research in Germany and the U.S. Scientometrics, 62(1), 67-85.

European Commission 2003. Third European Report on Science \& Technology Indicators 2003. Luxembourg: Office for Official Publications of the European Communities.

Frame, J D, M P Carpenter 1979. International research collaboration. Social Studies of Science, 9, 481-497.

Gaillard, Jacques, Venni V Krishna, Roland Waast eds. 1997. Scientific Communities in the Developing World. New Delhi, India and Thousand Oaks, California: Sage.

Gaillard, Jacques, Anna F Tullberg, in collaboration with E Zink,
B Porter, and H Hovmöller 2001. Questionnaire survey of African scientists. IFS grantees and INCO beneficiaries. Stockholm, Sweden: International Foundation for Science.

Glänzel, Wolfgang 2001. National characteristics in international scientific co-authorship relations. Scientometrics, 51(1), 69-115.

Glänzel, Wolfgang, András Schubert 2005. Domesticity and internationality in co-authorship, references and citations. Scientometrics, 65(3), 323-342.

Greenberg, Daniel S. 2002. New restrictions on foreign students. The Lancet, 359, 18 May 2002, 1757-1757.

Jappe, A 2007: Explaining international collaboration in global environmental change research. Scientometrics, 71(3), 367-390.

Katz, J Sylvan, Ben R Martin 1997. What is research collaboration? Research Policy, 26(1), 1-18.

Kennedy, Don 2002. Balancing terror and freedom. Science, 298(13), 2091-2091.

Laudel, Grit 2002. What do we measure by co-authorships? Research Evaluation, 11(1), 3-16.

LeClerc, M, J Gagné 1994. International scientific cooperation: The continentalization of science. Scientometrics, 31, 261-292.

Luukkonnen, Terttu, Olle Persson, Gunnar Sivertsen 1992. Understanding patterns of international scientific collaboration. Science, Technology and Human Values, 17(1), 101-126.

Luukkonen, Terttu, Robert J W Tijssen, Olle Persson, Gunnar Sivertsen 1993. The measurement of international scientific collaboration. Scientometrics, 28 (1), 15-36.

National Science Board (NSB) (eds.) 2006. Science and Engineering Indicators 2006, 1, Arlington, Virginia: National Science Foundation.

Okubo, Yoshiko, Michel Zitt 2004. Searching for research integration across Europe: a closer look at international and inter-regional collaboration in France. Science and Public Policy, 31(3), 213-226.

Pereira, Tiago Santos 2002. International dimension of research in Portugal: the European Research Area and beyond. Science and Public Policy, 29(6), 451-461.

Ricks, Ryan 2004. Science and security in the post-9/11 environment. Scientific publication policies. American Association for the Advancement of Science. Available at <http://www.aaas. org/spp/post911/publishing/>, last accessed 16 January 2007.

Schubert, A, T Braun 1990. International collaboration in the sciences, 1981-1985. Scientometrics, 19(1-2), 3-10.

Thorsteinsdóttir, O Halla 2000. External research collaboration in two small science systems. Scientometrics 49(1), 145-160.

Wagner, Carolyn S 2005. Six case studies of international collaboration in science. Scientometrics, 62(1), 3-26.

Wagner, Carolyn S, Loet Leydesdorff 2005. Mapping the network of global science: Comparing international co-authorships from 1990 to 2000, International Journal of Technology and Globalisation, 1(2), 185-208.

Wagner-Döbler, Roland 2001. Continuity and discontinuity of collaboration behaviour since 1800 - from a bibliometric point of view. Scientometrics, 52(3), 503-517.

Weingart, Peter 2006. Knowledge and inequality. In Inequalities of the World. New Theoretical Frameworks, Multiple Empirical Approaches, ed. Göran Therborn ed., pp. 163-190. London and New York: Verso. 